\title{
Molière, The Lavish Lovers. A Comedy Interspersed with Music and Ballet
}

\section{Laura Rescia}

\section{(2) OpenEdition}

1 Journals

\section{Edizione digitale}

URL: http://journals.openedition.org/studifrancesi/7546

DOI: $10.4000 /$ studifrancesi.7546

ISSN: 2421-5856

\section{Editore}

Rosenberg \& Sellier

\section{Edizione cartacea}

Data di pubblicazione: 1 décembre 2009

Paginazione: 617

ISSN: 0039-2944

\section{Notizia bibliografica digitale}

Laura Rescia, «Molière, The Lavish Lovers. A Comedy Interspersed with Music and Ballet», Studi Francesi [Online], 159 (LIII | III) | 2009, online dal 30 novembre 2015, consultato il 09 janvier 2021. URL: http:// journals.openedition.org/studifrancesi/7546 ; DOI: https://doi.org/10.4000/studifrancesi.7546

Questo documento è stato generato automaticamente il 9 janvier 2021.

\section{(c) $(1) \&$}

Studi Francesi è distribuita con Licenza Creative Commons Attribuzione - Non commerciale - Non opere derivate 4.0 Internazionale. 


\title{
Molière, The Lavish Lovers. A Comedy Interspersed with Music and Ballet
}

\author{
Laura Rescia
}

\section{NOTIZIA}

MOLIÈRE, The Lavish Lovers. A Comedy Interspersed with Music and Ballet, translation with Introduction and Notes by David EDNEY, Toronto, Centre for Re-formation and Renaissance Studies, 2009, pp. 286.

1 Come ci informa la quarta di copertina, l'A., professore emerito presso il dipartimento di Lingue e Linguistica dell'Università di Saskatchewan, è noto per aver tradotto pièces di teatro francese dell'Ancien Régime rappresentate in Canada e in diversi paesi anglofoni: questo suo ultimo si propone di introdurre il pubblico nordamericano ad uno specifico settore della produzione molieresca, quello delle comédies-ballets. Non entriamo nel merito della valutazione della traduzione (che viene presentata senza testo a fronte), non essendo questa di nostra competenza: ci limitiamo ad osservare la struttura del volume. Dopo una lunga introduzione, il lettore troverà una bibliografia estremamente selettiva, concepita per un pubblico anglofono specialmente interessato alle arti dello spettacolo, una discografia, alcune illustrazioni, relative a frontespizi, gravures d'epoca ma altresì fotografie di luoghi e rappresentazioni teatrali contemporanee de Les Amants magnifiques, il testo in traduzione, e un'appendice di testi coevi (tra cui il programma di sala delle prime rappresentazioni, una recensione apparsa sulla Gazette de France nel 1671, pagine dai Mémoires di Louis XIV relative ai divertimenti reali, e dell'abbé de Pure sulla funzione degli spettacoli), anch'essi in traduzione.

2 La lettura dell'introduzione conferma l'impressione di un volume concepito per un pubblico più interessato alla storia dello spettacolo che alla letteratura: dopo aver rivisitato la biografia di Molière alla ricerca di avvenimenti comprovanti l'influenza della musica e della danza sulla sua formazione, vengono approfonditi il suo rapporto 
con Lulli, il ruolo del balletto e l'importanza dei costumi e delle macchine nel suo teatro, e solo da ultimo le tematiche e il significato de Les Amants magnifiques, indagato con particolare interesse al rapporto tra Molière e il suo augusto committente. L'innegabile merito del lavoro di presentazione di questa comédie-ballet sta nella chiarezza espositiva, nella correttezza dell'uso delle fonti, nell'efficacia della sintesi sulle posizioni della recente critica molieresca, laddove il testo diviene spunto di ricerca per la ricostruzione filologica di uno spettacolo di fusione tra arti diverse. 